\title{
Desenvolvimento vegetativo, produção e qualidade dos frutos da laranjeira 'Folha Murcha' sobre seis porta-enxertos no Norte do Paraná
}

\author{
Vegetative growth, yield and quality fruits of the 'Folha Murcha' orange \\ on six rootstocks in North Parana, Brazil
}

\author{
Neusa Maria Colauto Stenzel ${ }^{1}$ Carmen Silvia Vieira Janeiro Neves ${ }^{2}$ Maria Gloria Nilo Gonzalez ${ }^{3}$ \\ Maria Brígida dos Santos Scholz ${ }^{4}$ José Carlos Gomes $^{5}$
}

\section{RESUMO}

Esta pesquisa avaliou em Londrina, PR, plantas de laranjeira 'Folha Murcha' sobre os porta-enxertos: laranjeira 'Caipira' (Citrus sinensis (L.) Osb.), limoeiro 'Cravo' (Citrus limonia Osb.), tangerineira 'Sunki' (Citrus sunki Hort. ex Tan.), limoeiro 'Rugoso da Flórida (Citrus jambhiri Lush.), tangerineira 'Cleópatra' (Citrus reshni Hort. ex Tan.) e limoeiro 'Volcameriano' (Citrus volkameriana Ten. e Pasq.). O delineamento experimental utilizado foi o de blocos ao acaso, seis porta-enxertos como tratamentos, cinco repetições e duas plantas por parcela. A altura, diâmetro $e$ volume da copa foram significativamente superiores em plantas enxertadas em laranjeira 'Caipira', quando comparadas com aquelas em limoeiro 'Volcameriano'. A menor diferença entre os diâmetros dos troncos abaixo/acima da enxertia ocorreu nas plantas em limoeiro 'Cravo' $e$ tangerineira 'Sunki'. A produção acumulada foi superior nas plantas sobre limoeiro 'Cravo'e laranjeira 'Caipira', sem mostrar significância estatística entre si, porém significativamente diferentes daquelas sobre tangerineira 'Cleópatra' e limoeiro 'Volcameriano'. A eficiência da produção não foi influenciada pelos porta-enxertos estudados. $O$ peso do fruto foi significativamente maior para as plantas em tangerineira 'Sunki', em comparação àqueles sobre limoeiros 'Cravo', limoeiro 'Rugoso da Flórida' $e$ limoeiro 'Volcameriano. Os sólidos solúveis totais (SST) apresentaram teores elevados nos frutos de laranjeiras 'Folha Murcha' sobre limoeiro 'Volcameriano' e limoeiro 'Cravo', sem diferirem entre si. A acidez titulável total (ATT), o ratio
(SST/ATT) e a cor do suco não foram influenciados pelos porta-enxertos testados. Os limões 'Cravo'e 'Volcameriano' proporcionaram valores de índice tecnológico significativamente maiores em relação aos porta-enxertos restantes. Os parâmetros de qualidade de suco avaliados estão dentro de padrões aceitáveis para variedades copa de laranja.

Palavras-chave: Citrus sinensis, volume da planta, peso dos frutos, índice tecnológico dos frutos.

\section{ABSTRACT}

This research evaluated, in Londrina, $P R$, Brazil, 'Folha Murcha' orange trees on the rootstocks: 'Caipira' orange (Citrus sinensis (L.) Osb.), 'Rangpur' lime (Citrus limonia Osb.), 'Sunki' mandarin (Citrus sunki Hort. ex Tan.), 'Florida' rough lemon (Citrus jambhiri Lush.), 'Cleopatra' mandarin (Citrus reshni Hort. ex Tan.), and 'Volkamer' lemon (Citrus volkameriana Ten. \& Pasq.). The experimental design was used as randomized blocks with six rootstocks as treatments, five replications and three plants per plot. Height, diameter, and canopy volume were significantly higher in trees budded on 'Caipira' orange, when compared with those budded on 'Volkamer' lemon. The smallest difference between trunk diameters below/above the bud occurred in trees on 'Rangpur' lime and 'Sunki' mandarin. Cumulative yield was superior for trees on 'Rangpur' lime and 'Caipira' orange, without showing statistical difference between themselves, but were significantly different from those on 'Cleopatra' mandarin

${ }^{1}$ Instituto Agronômico do Paraná (IAPAR), Área de Fitotecnia, CP 481, 86001-970, Londrina, PR, Brasil. E-mail: nstenzel@iapar.br

${ }^{2}$ Universidade Estadual de Londrina (UEL), Departamento de Agronomia, CP 6001, 86051-990, Londrina, PR, Brasil. E-mail: csvjneve@uel.br

${ }^{3}$ Sor Josefa 185, Las Condes, Santiago, Chile.

${ }^{4}$ IAPAR, Área de Ecofisiologia, CP 481, 86001-970, Londrina, PR, Brasil. E-mail: mbscholz@iapar.br

${ }^{5}$ IAPAR, Área de Bioestatística, CP 481, 86001-970, Londrina, PR, Brasil. E-mail: jcgomes@iapar.br 
and 'Volkamer' lemon. Yield efficiency was not influenced by the studied rootstocks. Fruit weight was significantly higher for trees on 'Sunki' mandarin, compared to those on 'Rangpur' lime, 'Florida' rough lemon, and 'Volkamer' lemon. Total soluble solids (TSS) showed high contents in fruits of 'Folha Murcha' orange on 'Volkamer' lemon and on 'Rangpur' lime, without differences between themselves. Total titratable acidity (TTA), (TSS/TTA) ratio, and juice color were not influenced by the rootstocks tested. 'Rangpur' lime and 'Volkamer' lemon provided significantly higher technological index values in relation to the other rootstocks. The juice quality parameters evaluated were within the acceptable standards for orange canopy varieties.

Key words: Citrus sinensis, canopy volume, fruits weight, fruits technological index.

\section{INTRODUÇÃO}

A laranjeira 'Folha Murcha’ é uma variedade de laranja que apresenta características agronômicas desejáveis, como a resistência ao cancro cítrico e maturação tardia (LEITE JÚNIOR, 1992), sendo a segunda mais plantada no Norte e Noroeste do Estado do Paraná.

A interação do porta-enxerto com a copa e o ambiente afeta as plantas de citros nas relações de água, nutrição mineral, crescimento, produtividade, resistência ou suscetibilidade às pragas, doenças e vários aspectos referente à qualidade do fruto (CASTLE et al., 1989).

O limoeiro 'Cravo'é o principal portaenxerto para a 'Folha Murcha' no Brasil e no Estado do Paraná, por influenciar boas características agronômicas às variedades copa. No entanto, este porta-enxerto é suscetível à gomose (FEICHTENBERGER, 1988), ao declínio (BERETTA \& ROSSETTI, 1990) e tem sido vulnerável à morte súbita (MÜLLER et al., 2002). A possibilidade de ocorrência de doenças e/ou condições adversas podem comprometer a cultura dos citros, quando há o uso generalizado de um único porta-enxerto, sendo portanto necessária a diversificação com outros porta-enxertos para evitar riscos (POMPEU JÚNIOR, 1991).

Pesquisas realizadas em São Paulo e Rio de Janeiro, referentes à avaliação da produção indicam porta-enxertos alternativos para a laranjeira 'Folha Murcha', como o limoeiro 'Volcameriano', Rugoso da Flórida', 'Bandhuri', ‘Cravo', 'Mazoe’ (semelhante ao limoeiro 'Rugoso da África') e tangerineira 'Sunki' (STUCHI et al., 2000 e BARROS et al., 1998). No entanto, os dados de experimentos realizados com relação ao comportamento das variedades copa de citros em diferentes porta-enxertos podem variar em função do clima, solo, doenças e práticas culturais, apresentando resultados freqüentemente divergentes.

No Paraná não há estudos com portaenxertos para a laranjeira 'Folha Murcha'. Considerando a importância da diversificação de portaenxertos e a necessidade de realização de testes regionais, este trabalho teve como objetivo avaliar o desempenho de plantas de ‘Folha Murcha' enxertadas em seis porta-enxertos no Norte do Estado do Paraná.

\section{MATERIAL E MÉTODOS}

A implantação do experimento ocorreu em maio de 1994, o qual foi conduzido por oito anos em área da Fazenda Escola da Universidade Estadual de Londrina (UEL), localizada no Norte do Estado do Paraná, município de Londrina ( $23^{\circ} 22^{\prime}$ S, $51^{\circ} 10^{\prime} \mathrm{W}$; altitude $585 \mathrm{~m})$. O clima do local está classificado segundo Köppen como Cfa. Os dados climáticos fornecidos pelo Instituto Agronômico do Paraná (IAPAR) informam que, em Londrina, a precipitação média anual é de $1.610 \mathrm{~mm}$, com tendência de concentração principalmente na primavera e verão, a temperatura média anual é de $21,2^{\circ} \mathrm{C}$ e umidade relativa média é $70,7 \%$. O solo está caracterizado como Latossolo Vermelho distroférrico (EMBRAPA, 1999), contendo $630 \mathrm{~g} \mathrm{~kg}^{-1}$ de argila, $180 \mathrm{~g} \mathrm{~kg}^{-1}$ de silte, $190 \mathrm{~g}$ $\mathrm{kg}^{-1}$ de areia, na camada de $0-25 \mathrm{~cm}$ do solo.

$\mathrm{O}$ experimento foi implantado no espaçamento de $7,0 \mathrm{~m} \times 4,0 \mathrm{~m}$, em delineamento experimental de blocos ao acaso, com seis tratamentos (porta-enxertos) e cinco repetições, sendo cada parcela composta por duas plantas. Na bordadura externa da área experimental foram colocadas plantas de laranjeira 'Pêra' enxertadas em limoeiro 'Cravo'. Os portaenxertos foram propagados por meio de sementes e enxertados com borbulhas procedentes de uma única planta de laranjeira 'Folha Murcha', sendo que as sementes e borbulhas foram obtidas de plantas da coleção de citros do IAPAR e as mudas produzidas na UEL. Foram avaliados os porta-enxertos: laranjeira 'Caipira' (Citrus sinensis (L.) Osb.), limoeiro 'Cravo'(Citrus limonia Osb.), tangerineira 'Sunki' (Citrus sunki Hort. ex Tan.), limoeiro 'Rugoso da Flórida’ (Citrus jambhiri Lush.), tangerineira 'Cleópatra' (Citrus reshni Hort. ex Tan.) e limoeiro 'Volcameriano' (Citrus volkameriana Ten. e Pasq.). O experimento foi conduzido sem irrigação e as plantas manejadas conforme recomendação técnica para o cultivo comercial de citros (INSTITUTO AGRONÔMICO DO PARANÁ, 1992).

O desenvolvimento vegetativo das plantas (altura, diâmetro da copa e diâmetro do tronco acima e 
abaixo do ponto de enxertia) foram avaliados em maio/ 2002. A altura e o diâmetro das copas foram medidos com uma régua métrica graduada em centímetros, sendo que a altura foi tomada desde o solo até o topo da planta, e o diâmetro da copa medido no sentido paralelo e perpendicular à linha de plantio e estimada a média. O diâmetro do tronco foi avaliado cinco centímetros acima e abaixo da linha de enxertia por meio de fita diamétrica. Também foi estimada a relação do diâmetro do tronco abaixo/acima da enxertia, para avaliar a diferença entre os diâmetros do porta-enxerto e enxerto. Determinou-se ainda, o volume da copa pela fórmula proposta por MENDEL (1956): $\mathrm{V}=2 / 3$ ð $\mathrm{R}^{2} \mathrm{H}$, onde $\mathrm{V}$ representa o volume $\mathrm{m}^{3}$, $\mathrm{R}$ o raio da copa (m) e $\mathrm{H}$, a altura da planta (m). A produção $\left(\mathrm{kg} \mathrm{planta}^{-1}\right)$ foi avaliada anualmente, e para obter a produção acumulada (kg planta ${ }^{-1}$ ) foram somadas as safras de 1998 a 2002. A eficiência da produção (1998 a 2002) foi estimada dividindo-se a produção (kg planta $\left.{ }^{-1}\right)$ pelo volume da copa $\left(\mathrm{m}^{3}\right)$ para cada porta-enxerto.

A qualidade dos frutos foi avaliada na quinta safra, em janeiro de 2003, período em que as plantas enxertadas em limoeiro 'Cravo' apresentavam ratio (sólidos solúveis totais/acidez titulável total) próximo a 12. Foram coletados dez frutos em cada parcela, de forma aleatória nos quatro quadrantes das plantas, a uma altura de 1,00 a 2,50 m de altura do solo. No laboratório do IAPAR, os frutos foram pesados e, em seguida, extraído o suco em um espremedor elétrico para as seguintes determinações: rendimento do suco em percentagem (relação entre o peso do suco e o peso do fruto); sólidos solúveis totais (SST), medidos em ${ }^{\circ}$ Brix por meio de um refratômetro manual, com os valores corrigido para $20^{\circ} \mathrm{C}$; acidez titulável total (ATT) por titulação com $\mathrm{NaOH}$ a 0,1 N (AOAC, 1990), sendo os resultados expressos em percentagem de ácido cítrico.
Também foram estimados o ratio (SST/ATT) e o índice tecnológico (IT), o qual foi obtido mediante a equação: $\mathrm{IT}$ = rendimento em suco $\mathrm{x}$ sólidos solúveis totais x 40,8 / 10.000, calculando-se assim, o teor de sólidos solúveis totais em uma caixa de colheita de frutos de 40,8 kg. No laboratório da COROL CITRUS, a vitamina $\mathrm{C}$ expressa em $\mathrm{mg} \%$, foi determinada em fevereiro de 2003, por titulometria com iodo (IAL, 1985). A cor do suco foi avaliada pela comparação de tubos padrões da série OJ (orange juice) do Departamento de Agricultura dos Estados Unidos (USDA) (KIMBALL, 1991).

Os resultados obtidos foram analisados utilizando-se o programa SAS (SAS INSTITUTE INC., 2001) para a análise de variância, a qual foi complementada pelo teste de Duncan a 5\% de probabilidade de erro.

\section{RESULTADOS E DISCUSSÃO}

Na tabela 1, encontram-se os resultados das avaliações com relação ao desenvolvimento vegetativo das plantas oito anos após o plantio. As plantas enxertadas em laranjeira ‘Caipira' apresentaram altura superior com diferença significativa daquelas sobre limoeiro 'Volcameriano', porém ambos não foram diferentes daquelas nos demais porta-enxertos. Os valores de diâmetro da copa foram maiores nas plantas em laranjeira 'Caipira', tangerineira 'Cleópatra' e limoeiro 'Rugoso da Flórida', evidenciando diferenças significativas em comparação aos limões ‘Cravo’ e ‘Volcameriano’. Dados de estudo realizado por STUCHI et al. (2000), informam que não houve diferença para dos parâmetros de altura de planta e diâmetro da copa, respectivamente, entre as laranjeiras 'Folha Murcha' sobre limoeiro 'Volcameriano' (3,25m e 3,58m) , tangerineira 'Cleópatra' (3,51m e 3,75m), limoeiro

Tabela 1 - Altura da planta, diâmetro, volume da copa, diâmetro do tronco abaixo e acima do ponto de enxertia e relação dos diâmetros dos troncos em 2002 de plantas de laranjeira 'Folha Murcha', enxertadas sobre seis porta-enxertos em Londrina, PR.

\begin{tabular}{|c|c|c|c|c|c|c|}
\hline Porta-Enxertos & $\begin{array}{l}\text { Altura da } \\
\text { planta } \\
\text { (m) }\end{array}$ & $\begin{array}{l}\text { Diâmetro } \\
\text { da copa } \\
\text { (m) }\end{array}$ & $\begin{array}{l}\text { Volume } \\
\text { da copa } \\
\left(\mathrm{m}^{3}\right)\end{array}$ & $\begin{array}{l}\text { Diâmetro do tronco } \\
\text { abaixo do ponto de } \\
\text { enxertia } \\
(\mathrm{cm})\end{array}$ & $\begin{array}{l}\text { Diâmetro do tronco } \\
\text { acima do ponto de } \\
\text { enxertia } \\
(\mathrm{cm})\end{array}$ & $\begin{array}{l}\text { Relação diâmetro do tronco } \\
\text { abaixo/acima do ponto de } \\
\text { enxertia }\end{array}$ \\
\hline Laranjeira ‘Caipira' & $3,7^{*} \mathrm{a}$ & $3,8 \mathrm{a}$ & 27,5 a & 17,2 a & 16,0 a & $1,07 \mathrm{ab}$ \\
\hline Limoeiro ‘Cravo’ & $3,6 \mathrm{ab}$ & 3,4 bc & $22,1 \mathrm{c}$ & $14,6 \mathrm{c}$ & $14,5 \mathrm{~b}$ & $1,00 \mathrm{c}$ \\
\hline Tangerineira 'Sunki' & $3,6 \mathrm{ab}$ & $3,5 \mathrm{ab}$ & 23,6 bc & $15,8 \mathrm{~b}$ & $15,3 \mathrm{ab}$ & 1,03 bc \\
\hline Limoeiro ‘Rugoso da Flórida’ & $3,6 \mathrm{ab}$ & 3,7 a & 25,2 abc & $16,6 \mathrm{ab}$ & 15,5 a & $1,07 \mathrm{ab}$ \\
\hline Tangerineira ‘Cleópatra’ & $3,6 \mathrm{ab}$ & 3,7 a & $25,7 \mathrm{ab}$ & $16,2 \mathrm{ab}$ & $15,3 \mathrm{ab}$ & $1,06 \mathrm{ab}$ \\
\hline Limoeiro ‘Volcameriano’ & $3,4 \mathrm{~b}$ & $3,2 \mathrm{c}$ & $18,3 \mathrm{~d}$ & 14,6 c & $13,4 \mathrm{c}$ & 1,09 a \\
\hline CV (\%) & 3,6 & 4,2 & 22,1 & 14,6 & 14,5 & 3,4 \\
\hline
\end{tabular}

* Médias seguidas com a mesma letra na coluna não diferem entre si pelo teste de Duncan a 5\% de significância. 
'Rugoso da Flórida' (3,33 e 3,61), limoeiro 'Cravo' (3,13m e 3,43m) e tangerineira 'Sunki' (3,28m e 3,38m). O cálculo do volume da copa no presente trabalho demonstrou que, embora a laranjeira 'Caipira' tenha proporcionado um volume maior, não ocorreu diferença significativa para as copas das plantas em tangerineira 'Cleópatra' e limoeiro 'Rugoso da Flórida', porém as plantas sobre limoeiro 'Volcameriano' apresentaram o menor valor verificando-se significância estatística para com os outros porta-enxertos avaliados. BARROS et al. (1998) também observaram maior desenvolvimento das plantas de laranjeira 'Folha Murcha’ enxertadas em limoeiro ‘Rugoso da Flórida’ e tangerineira 'Cleópatra'.

A avaliação de diâmetro do tronco abaixo do ponto de enxertia apresentou valor significativamente maior nas plantas enxertadas em laranjeira Caipira, em comparação aos porta-enxertos limoeiro 'Cravo', tangerineira 'Sunki' e limoeiro 'Volcameriano'. O resultado do diâmetro do tronco acima do ponto de enxertia mostraram que as plantas em laranjeira 'Caipira' e limoeiro 'Rugoso da Flórida', obtiveram diâmetros dos troncos significativamente superiores às plantas sobre limoeiro 'Cravo' $\mathrm{e}$ 'Volcameriano'. Quanto à relação das medidas dos diâmetros dos troncos abaixo/acima da enxertia, observa-se que as plantas sobre limoeiro 'Cravo' e tangerineira 'Sunki' apresentaram a relação mais próxima de 1 , ou seja, com as menores diferenças entre os diâmetros, sem diferirem entre si, porém foram significativamente diferentes das plantas em limoeiro 'Volcameriano', as quais obtiveram o maior valor na relação entre diâmetros (Tabela 1). Essa diferença entre os diâmetros dos troncos nas combinações de copa e porta-enxerto é um indicativo de incompatibilidade entre as espécies estudadas devido as suas características genéticas (CASTLE et al., 1989).
Os dados referentes à produção anual, acumulada e eficiência da produção, de cinco safras, estão apresentados na tabela 2. Nos resultados de produção anual, observa-se que, na safra de 2001, houve baixa produção para as plantas em todos os porta-enxertos testados, provavelmente devido à produção elevada da safra de 2000 , que, associada às estiagens do período, pode ter gerado condições desfavoráveis para o acúmulo de reservas, afetando o florescimento da safra seguinte. As produções acumuladas das laranjeiras 'Folha Murcha' enxertadas em limoeiro 'Cravo' (261,6kg) e laranjeira 'Caipira' (268,8kg) foram superiores sem significância estatística entre si, no entanto ambas foram significativamente diferentes das plantas sobre tangerineira 'Cleópatra' (221,2kg) e limoeiro ‘Volcameriano’ (204,4kg), os quais induziram as menores produções. A eficiência da produção não foi influenciada pelos porta-enxertos testados.

A partir dos dados de STUCHI et al. (2000), nas condições de Bebedouro, SP, observa-se divergência dos resultados deste experimento, pois a produção acumulada foi significativamente superior nas plantas de 'Folha Murcha' enxertadas em limoeiro 'Volcameriano' (270,13kg planta-1), quando comparadas àquelas em tangerineira 'Cleópatra', tangerineira 'Sunki' e limoeiro 'Cravo' que apresentaram produção variando 138,55 a 163,58 $\mathrm{kg}$ planta $^{-1}$. Para BARROS et al. (1998), no Estado do Rio de Janeiro, as maiores produções de 'Folha 'Murcha' foram propiciadas pelos porta-enxertos limoeiro 'Volcameriano', limoeiro 'Mazoe', tangerineira 'Sunki' e limoeiro ‘Cravo'; e os dados de eficiência da produção não evidenciaram diferença significativa para as plantas em limoeiro 'Volcameriano', tangerineira 'Sunki' e limoeiro ‘Cravo'.

Os resultados relacionados à qualidade dos frutos avaliados na quinta safra podem ser observados na tabela 3 .

Tabela 2 - Produção anual de cinco safras (1998 a 2002) de plantas de laranjeira ‘Folha Murcha’ sobre seis porta-enxertos em Londrina, PR.

\begin{tabular}{|c|c|c|c|c|c|c|c|}
\hline \multirow[t]{2}{*}{ Porta-Enxertos } & \multicolumn{5}{|c|}{$\begin{array}{c}\text { Produção anual } \\
\text { (kg/planta) }\end{array}$} & \multirow{2}{*}{$\begin{array}{c}\begin{array}{c}\text { Produção } \\
\text { acumulada } \\
\text { (kg/planta) }\end{array} \\
1998 \text { a } 2002\end{array}$} & \multirow{2}{*}{$\begin{array}{c}\begin{array}{c}\text { Eficiência da } \\
\text { produção } \\
\left(\mathrm{kg} \mathrm{m}^{3}\right)\end{array} \\
1998 \text { a } 2002\end{array}$} \\
\hline & 1998 & 1999 & 2000 & 2001 & 2002 & & \\
\hline Laranjeira ‘Caipira’ & $17,8^{*} \mathrm{~b}$ & 33,5 a & 111,3 a & $10,2 \mathrm{~b}$ & 96,0 a & 268,8 a & $3,56 \mathrm{a}$ \\
\hline Limoeiro ‘Cravo’ & 27,5 a & $33,1 \mathrm{a}$ & $106,7 \mathrm{ab}$ & $15,6 \mathrm{ab}$ & $78,7 \mathrm{ab}$ & 261,6 a & $3,64 \mathrm{a}$ \\
\hline Tangerineira 'Sunki' & $18,3 \mathrm{~b}$ & $36,4 \mathrm{a}$ & 96,7 bc & $14,9 \mathrm{ab}$ & $86,5 \mathrm{ab}$ & $252,9 \mathrm{ab}$ & $3,64 \mathrm{a}$ \\
\hline Limoeiro 'Rugoso da Flórida' & $18,0 \mathrm{~b}$ & $32,2 \mathrm{a}$ & 93,1 bc & $10,9 \mathrm{~b}$ & 96,6 a & $250,9 \mathrm{ab}$ & 3,86 a \\
\hline Tangerineira ‘Cleópatra’ & $16,6 \mathrm{~b}$ & 27,9 a & 88,7 c & $10,5 \mathrm{~b}$ & $77,5 \mathrm{ab}$ & 221,2 bc & $3,06 \mathrm{a}$ \\
\hline Limoeiro 'Volcameriano' & $23,0 \mathrm{ab}$ & 23,3 a & $72,9 \mathrm{~d}$ & 17,4 a & $67,9 \mathrm{~b}$ & 204,4 c & $3,72 \mathrm{a}$ \\
\hline CV (\%) & 29,1 & 33,1 & 10,4 & 29,6 & 18,4 & 10,8 & 20,0 \\
\hline
\end{tabular}

“Médias seguidas com a mesma letra na coluna não diferem entre si pelo teste de Duncan a 5\% de significância. 
Tabela 3 - Peso dos frutos, rendimento, sólidos solúveis totais (SST), acidez titulável total (ATT), ratio (SST/ATT) e índice tecnológico em janeiro/03; vitamina C e cor do suco em fevereiro/03 de laranja 'Folha Murcha' sobre seis porta-enxertos em Londrina, PR.

\begin{tabular}{|c|c|c|c|c|c|c|c|c|}
\hline Porta-Enxertos & $\begin{array}{l}\text { Peso médio } \\
\text { dos frutos } \\
\text { (g) }\end{array}$ & $\begin{array}{l}\text { Rendimento } \\
\text { em suco (\%) }\end{array}$ & $\begin{array}{c}\text { Sólidos } \\
\text { solúveis } \\
\text { totais ( }{ }^{\circ} \text { Brix) }\end{array}$ & $\begin{array}{l}\text { Acidez } \\
\text { titulável total } \\
\text { (ATT) } \\
\text { (\%) }\end{array}$ & $\begin{array}{c}\text { Ratio } \\
\text { (SST/ATT) }\end{array}$ & $\begin{array}{c}\text { Vitamina C } \\
\text { (mg \%) }\end{array}$ & $\begin{array}{c}\text { Índice } \\
\text { tecnológico Kg } \\
\text { SST/_caixa }\end{array}$ & $\begin{array}{c}\text { Cor do suco } \\
\text { (escore) }\end{array}$ \\
\hline Laranjeira 'Caipira' & $163,2^{*}$ abc & $48,6 \mathrm{~b}$ & 10,2 bc & $0,78 \mathrm{a}$ & $13,1 \mathrm{a}$ & 38,81 a & 2,01 bc & 37 \\
\hline Limoeiro ‘Cravo’ & 149,6cd & $53,8 \mathrm{a}$ & $10,6 \mathrm{ab}$ & 0,79 a & 13,5 a & $40,10 \mathrm{a}$ & 2,33 a & 37 \\
\hline Tangerineira 'Sunki' & $170,8 \mathrm{a}$ & $49,1 \mathrm{~b}$ & $9,6 \mathrm{c}$ & $0,77 \mathrm{a}$ & $12,5 \mathrm{a}$ & 39,17 a & $1,91 \mathrm{~cd}$ & 37 \\
\hline Limoeiro 'Rugoso da Flórida' & 153,6 bcd & $48,2 \mathrm{~b}$ & $9,5 \mathrm{c}$ & $0,75 \mathrm{a}$ & $12,7 \mathrm{a}$ & 40,24 a & $1,87 \mathrm{~d}$ & 37 \\
\hline Tangerineira ‘Cleópatra’ & $166,2 \mathrm{ab}$ & $52,1 \mathrm{a}$ & $9,8 \mathrm{c}$ & $0,75 \mathrm{a}$ & $13,0 \mathrm{a}$ & $36,96 \mathrm{~b}$ & $2,08 \mathrm{~b}$ & 37 \\
\hline Limoeiro ‘Volcameriano’ & $142,0 \mathrm{~d}$ & $50,0 \mathrm{~b}$ & 11,0 a & 0,85 a & 13,0 a & 40,29 a & 2,25 a & 37 \\
\hline CV (\%) & 7,2 & 8,0 & 4,6 & 9,5 & 7,7 & 3,4 & 4,6 & \\
\hline
\end{tabular}

${ }^{*}$ Médias seguidas com a mesma letra na coluna não diferem entre si pelo teste de Duncan a 5\% de significância.

O maior peso médio dos frutos ocorreu nas plantas enxertadas em tangerineira 'Sunki' (170,8g), as quais diferiram significativamente daquelas em limões 'Cravo' (149,6g), 'Rugoso da Flórida' (153,6g) e 'Volcameriano’ (142,0g). O rendimento em suco foi maior nos frutos procedentes de plantas em limoeiro ‘Cravo’ e tangerineira 'Cleópatra', não evidenciando diferença significativa entre si, porém apresentaram significância estatística para os demais porta-enxertos. Os dados de peso de fruto obtidos por STUCHI et al. (2000) para plantas de 'Folha Murcha' enxertadas em tangerineira 'Sunki' e limões 'Cravo', 'Rugoso da Flórida’e ‘Volcameriano’ foram superiores aos obtidos no presente trabalho, variando de 221,0 a 219,0g. Resultado similar quanto ao rendimento de suco, também foi relatado por LEITE JÚNIOR (1992) em frutos de plantas de laranjeira ‘Folha Murcha’ sobre limoeiro ‘Cravo' .

Com relação aos sólidos solúveis totais (SST), os teores mais elevados ocorreram nos frutos produzidos em laranjeiras 'Folha Murcha' sobre os limões ‘Volcameriano’ e ‘Cravo’, sem diferenciarem entre si, os quais mostraram diferença significativa para aqueles frutos de plantas enxertadas em tangerineira 'Sunki', tangerineira 'Cleópatra' e limoeiro 'Rugoso da Flórida'. Os porta-enxertos não influenciaram a acidez titulável total (ATT) e o ratio (SST/ATT), que apresentaram valores dentro do padrão aceitável para laranjas conforme (DI GIORGI et al., 1993).

Os valores do índice tecnológico (IT) obtidos no suco de frutos das plantas em limoeiro 'Volcameriano' (2,25kg SST/caixa) e limoeiro ‘Cravo’ (2,33kg SST/caixa), foram significativamente superiores aos frutos produzidos sobre os demais porta-enxertos, os quais apresentaram variação de 1,87 a 2,08kg SST/caixa. A vitamina $\mathrm{C}$ apresentou teor significativamente menor nos frutos de plantas que tiveram como porta-enxerto a tangerineira 'Cleópatra', quando comparada aos portaenxertos restantes, os quais não diferiram entre si. Os sucos dos frutos apresentaram cor com escore 37, para todos os porta-enxertos testados. Os resultados de SST, IT, vitamina C e cor do suco estão próximos daqueles obtidos por DONADIO et al. (1999) para 'Folha Murcha' em citrumelo 'Swingle': IT de 2,14 kg de SST/caixa), vitamina C de 39,67 mg \% e cor do suco com pontuação de 37,2. STUCHI et al. (2000), em Bebedouro, SP, quando estudaram a laranjeira 'Folha Murcha' sobre tangerineiras 'Cleópatra' e 'Sunki', limões 'Cravo', 'Volcameriano’, 'Rugosos da Flórida e Nacional', constataram valores semelhantes aos observados no presente trabalho para as variáveis de rendimento em suco (51,9 a 54,1\%) e IT (2,12 a 2,54 kg de SST/caixa), sendo que, para a cor do suco, obtiveram escore 37 nos fruto das plantas de 'Folha Murcha' sobre limoeiro ‘Volcameriano', e 38 para os frutos produzidos nos demais porta-enxertos; porém, os valores de SST foram mais elevados e os teores de acidez mais baixos, obtendo valores de ratio (SST/ATT) maiores que os observados neste trabalho, possivelmente devido às condições ambientais mais favoráveis de temperatura e disponibilidade hídrica do solo.

\section{CONCLUSÕES}

O limoeiro ‘Cravo’ em comparação aos outros porta-enxertos proporciona às plantas de 'Folha Murcha’ os seguintes indicativos favoráveis: produção acumulada elevada, volume de copa intermediário, baixa relação entre os diâmetros dos troncos abaixo e acima da enxertia e índice tecnológico superior.

\section{AGRADECIMENTOS}

Stenzel, bolsista da Empresa Brasileira de Pesquisa Agropecuária (EMBRAPA). Neves, bolsista em produtividade do Conselho Nacional de Desenvolvimento Científico e Tecnológico (CNPq). 


\section{REFERÊNCIAS}

AOAC - ASSOCIATION OF OFFICIAL ANALYTICAL CHEMISTS. Official methods of analysis. 15.ed. Arlington, 1990. 1298p.

BARROS, J.C.S.M. et al. Porta-enxertos para laranjeira Folha Murcha. In: CONGRESSO BRASILEIRO DE FRUTICUlTURA, 15., 1998, Poços de Caldas, MG. Resumos... Lavras: UFLA, 1998. p.271.

BERETTA, M.J.; ROSSETTI, V. Declínio dos citros - uma doença transmissível. In: DONADIO, L.C. SEMINÁRIO INTERNACIONAL DE CITROS - PORTA-ENXERTOS, 1990, Bebedouro. Anais... Jaboticabal: FUNEP, 1990. p.211-221.

CASTLE, W.S. et al. Rootstocks for Florida Citrus. Institute of Food and Agricultural Sciences. Gainesville: University of Florida, 1989. 47p.

DI GIORGI, F. et al. Qualidade da laranja para industrialização. Laranja, Cordeirópolis, v.14, n.1, p.97-118. 1993.

DONADIO, L.C. et al. Novas variedades e clones de laranja doce para indústria. Jaboticabal: UNESP/FUNEP/ EECB, 1999. 42p. (Boletim Citrícola).

EMBRAPA - Empresa Brasileira de Pesquisa Agropecuária. Sistema Brasileiro de classificação de solos. Rio de janeiro: Embrapa Solos, 1999. 412p.

FEICHTENBERGER, E. Principais doenças fúngicas dos citros. In: SIMPÓSIO DE CITRICULTURA, 3., 1988, Jaboticabal. Anais... Jaboticabal: FCAV, FUNEP, 1988. p.117-136.
IAL - INSTITUTO ADOLFO LUTZ. Normas Analíticas do Instituto Adolfo Lutz. Métodos químicos e físicos para análise de alimentos. 3.ed. São Paulo: IMESP, 1985. V.2, p.392-395.

INSTITUTO AGRONÔMICO DO PARANÁ. A citricultura no Paraná. Londrina: IAPAR, 1992. 288p. (Circular, 72).

KIMBALL, D.A. Citrus processing: quality control and technology. New York: Van Nostrand Reinhold, 1991. 473p.

LEITE JÚNIOR, R.P. Cultivares copa e porta-enxertos. In: IAPAR. A citricultura no Paraná. Londrina, 1992. 288p. (Circular, 72).

MENDEL, K. Rootstock-scion relationships in Shamouti trees on light soil. Ktavim, Rehovot, v.6, p.35-60, 1956.

MÜLLER, G.W. et al. Morte súbita dos citros: uma nova doença na citricultura brasileira. Laranja, Cordeirópolis, v.23, n.2, p.371-386, 2002.

POMPEU JÚNIOR, J. Porta-enxertos. In: RODRIGUEZ, O. et al. Citricultura brasileira. 2.ed. Campinas: Fundação Cargill, 1991. p.265-280.

SAS INSTITUTE INC. SAS/STAT User's Guide. Version 8.2. Cary, NC, 2001. 943p.

STUCHI, E.S. et al. Avaliação da laranjeira 'Folha Murcha' (Citrus sinensis (L) Osbeck) sobre dez porta-enxertos em Bebedouro, SP. Revista Brasileira de Fruticultura, Jaboticabal, v.22, n.3, p.446-453, 2000. 